\title{
Commentary on Empirically-Based Outpatient Treatment for a Patient at Risk for Suicide: The Case of "John"
}

A Model Case of Suicide Intervention JOHN KALAFAT ${ }^{\text {a,b }}$

${ }^{\text {a }}$ Rutgers - The State University of New Jersey

b Correspondence concerning this article should be addressed to John Kalafat, Rutgers University, Graduate School of Applied and Professional Psychology, 152 Frelinghuysen Road, Piscataway, NJ 08854. Email: kalafat@rci.rutgers.edu

\begin{abstract}
Case studies provide important insight into the actual work within clinical settings. In Craig Bryan's (2007) detailed description of outpatient treatment of a suicidal client, the author illustrates several important elements of a comprehensive treatment approach for such clients. One of these elements is an active approach that fosters the client's collaboration in addressing his concerns. Also, the treatment is grounded in current conceptual and empirical bases. In addition, the treatment starts with a thorough assessment that yields a flexible range of specific treatment approaches which are responsive to the exigencies of the clinical situation. These treatment approaches involve connecting to the client through his pain, strategies for coping with anxiety and suicidal feelings, mobilization of supports, cognitive skills training, and increasing tolerance for suffering that at times cannot be avoided.
\end{abstract}

Key words: suicide treatment; collaborative treatment; outpatient suicide therapy

The relatively recent emergence of evidence-based approaches to the prevention and treatment of suicidal behavior has prompted the need for "thick description" (Geertz, 1979) of the application of these approaches in practice. For example, in 2006, the American Foundation for Suicide Prevention (http://www.afsp.org) completed its Suicide Data Bank project (AFSP, 2007) in which detailed information, including narrative case reports, was collected from 36 therapists who had lost a patient to suicide. The project examined the course of treatment, the events leading up to the suicide, the patients' emotional state prior to the suicide, and the therapists' reactions to the suicide. The project has yielded important information through such publications as "Desperation and Other Affective States in Suicidal Patients" (Hendin et al., 2004) and "Problems in Psychotherapy With Suicidal Patients" (Hendin et al., 2006). Likewise, Bryan's (2007) rich case study contributes substantially to our understanding of the application of several conceptually and empirically based approaches to the treatment of suicidal patients. Specifically, Bryan's case description illustrates several common characteristics of suicidal 
individuals, an effective treatment style or approach for working with suicidal patients, and important components of both effective crisis and treatment plans for suicidal patients.

\section{THE SUICIDAL CLIENT}

Crises occur when the demands of a situation exceed the individual's capacity to respond due to a combination of characteristics of the situation and the particular state and/or trait vulnerabilities of the individual. It appears that central characteristics of John are the importance of an ability maintain control and actively influence events, which quite likely influenced his choice of medicine and the military. He then found himself in a situation that directly challenged those abilities. The inherently chaotic characteristics of the field hospital, coupled with the wellintentioned policy of triaging casualties according to medical need rather than combatant status, and ensconced in a war without a clear basis or goal produced a situation that was inherently not only uncontrollable but ultimately irrational and with no clear exit. This situation not only matched John's particular vulnerabilities but also produced three primary characteristics of the suicidal situation: it was intolerable, inescapable, and interminable (Chiles \& Strosahl, 1995). The situation also produced other contributing factors to crisis, such as overload, and of suicide, such as feeling trapped. In addition, the stigma attached to suicide in general as well as concerns about the impact of suicidality on one's military career combined to block John's sharing his feelings. This engendered what Sullivan (1970) called the "fallacy of uniqueness", which Bryan addressed. This produced another characteristic of suicidality: increasing isolation. Thus, John could not have known that feeling overwhelmed and trapped were normal responses to an abnormal situation and he blamed himself for his inability to cope, which produced yet another contributing factor to suicide: shame (Lester, 1997). Bryan's description of the feedback loop of increasing stress and suicidal feelings -- which prompted such negative outcomes as withdrawal, termination of exercise and other pleasurable activities, and marital stress -- illustrates the downward spiral in which suicide becomes an option to both regain control and end the pain. Within the litany of reasons for dying, there are usually simultaneous reasons for living. For John, some initial reasons for living included the fact that (a) suicide remained dystonic (he wanted to get rid of the suicidal thoughts), and (b) the concerned intervention of his supervisor (that I take as an outcome of the United States Air Force's [USAF's] suicide prevention program, which emphasizes a "competent community" in which members care for each other [Knox et al., 2003]).

Finally, it must be noted that John's nascent suicidal feelings were substantially exacerbated by his redeployment upon his return to the U.S. to a hospital situation that closely mimicked the conditions that gave rise to his original trauma. This raises a policy issue in regard to possible iatrogenic effects of the USAF redeployment procedures. Through its systemic or community approach to suicide prevention, the USAF has taken the lead in addressing military policies that could impair the effective response to suicide, and this might be another consideration to explore. 
It is important to understand the particular stresses and vulnerabilities that give rise to specific risk factors for individual clients, since these must be explicitly addressed in the treatment, as will be seen in the following sections. This fact has led to a reframe of warning signs as "invitations" that must be explored by Applied Suicide Intervention Skills Training (ASIST), a leading suicide training program (Ramsay, Tanny, Lang, \& Kinzel, 2004). "Warning signs" implies keeping away, whereas "invitations" imply moving closer. Thus, Bryan stated, "the primary task for the clinician is to move towards the suicidal patient" (pg. 19). The initial evidence of this is Bryan's persistence in his questioning of John's suicidal ideation (pg. 11). Such persistence is one of the hallmarks of effective work with suicidal clients, which are further reviewed in the following section.

\section{THE THERAPEUTIC APPROACH}

There is a consensus among several experts in crisis intervention and suicide (cf Chiles \& Strosahl, 1995; Jobes, 2006; Rudd, Joiner \& Rajab, 2001), as well as feedback from clients (Echterling \& Hartsough, 1989; Gould, Kalafat, Munfakh, \& Kleinman, 2007; Lee, 1999) that an active, explanatory approach is preferable to a more passive, "blank screen" approach. While empathy, warmth, and genuineness (Rogers, 1957) remain important characteristics of any treatment, a traditional Rogerian approach would not be appropriate for either crisis situations or for work with military personnel. There is also a consensus around a collaborative approach that (a) fosters agency and motivation, and that (b) supports crises as opportunities for growth in the sense of being critical antidotes to the sense of helplessness and incompetence that crises foster (Ellis, 2004; Jobes, 2006; Kalafat, 2002). Bryan's active, engaged style is illustrated by his explanation of the conditions for hospitalization, his sharing of the USAF's more supportive attitude toward help-seeking for personal concerns, his normalization of John's response to the multiple changes in his life, and his use of bibliotherapy.

At the same time, suicide also calls for directiveness in response to imminently lifethreatening situations as well as some non-negotionable conditions for the outpatient treatment of suicidal clients. Thus, the clinician reserves the option of involuntary hospitalization as a last resort to preserve life in acute situations; and Bryan responded to John's noncompliance by negotiating a "Commitment to Treatment" agreement. Rather than attenuating client agency, these approaches demonstrate the commitment of the therapist and his or her "movement toward the client."

In fact, there are several dialectics in working with suicidal clients that are illustrated in this case. While recognizing common warning signs and risk factors for suicide, normalizing a client's reactions, and addressing the fallacy of uniqueness, one must identify and acknowledge the client's unique experience of his or her problem, stressors, and suicidality. While collaboration is a key to recovery (what trainers in one crisis center called a successful experience for the client versus the therapist), one must be prepared to be directive when necessary but always seek to fade that directiveness in the client's interest. One must choose where to take a stand (e.g., by removing access to means where possible) and where to reduce insistence (e.g., in regard to medication). And, as Jobes (2006) noted, while the therapist must 
J. Kalafat

Pragmatic Case Studies in Psychotherapy, http://pcsp.libraries.rutgers.edu

Volume 3, Module 2, Article 2, pp. 41-49, 05-02-07 [copyright by authors]

concede that the client can ultimately decide whether or not to try suicide, the client must agree to hold off on attempting suicide as part of committing to an effort to find other solutions.

\section{THE CRISIS PLAN}

The initial tasks of treatment of suicidal clients are the mutually reinforcing ones of establishing a connection and rapport with the client and conducting an assessment. Without rapport, the assessment may lack validity. An assessment that leads to a mutual understanding of the client's concerns and suicidality makes the client feel understood and reinforces the relationship. The next task involves the development of a crisis plan, which has both common elements and elements tailored to the issues and context identified in the assessment. The crisis plan is based on acknowledging that suicidal feelings come and go and may begin to feel uncontrollable. This represents an acknowledgement of the client's suicidality rather than a discount of it implied by the ineffective, no-suicide contract. It also begins the process of enhancing the client's sense of agency. Thus, John's plan contains the common crisis plan elements of accessing his own internal and external supports for addressing suicidal feelings before contacting formal resources. The mobilization and involvement of natural resources is an essential crisis strategy, and Bryan obtained a release to involve and educate John's spouse as part of his treatment. Among her roles was assisting in the removal of access to lethal means in the form of John's firearm, as the presence of a firearm in the home has been documented to increase the risk for suicide (Brent \& Bridge, 2003). The plan acknowledges that access to formal resources is acceptable by the provision for increased contact with the therapist between sessions. Finally, Bryan noted a critical part of treatment: documentation of all assessment results, their connection to the crisis and treatment plans, and all treatment decisions. Crisis plans provide both structure and support that counter the sense of confusion and feeling overwhelmed that characterize crises.

\section{THE TREATMENT PLAN}

\section{Initial Tasks}

The initial phase of treatment illustrates strategies that are important for working with suicidal clients as well as for any crisis or short-term treatments. One of these is to connect assessment and treatment, and the Collaborative Assessment and Management of Suicidality (CAMS) model and the related Suicide Status Form (SSF) that Bryan employed is designed to promote this. In his words,

One of the great benefits of the CAMS approach is the intimate connection of assessment and treatment. By completing the SSF, John and I had not only gained an understanding of his unique suicide risk, but had simultaneously identified those areas of John's life that could be mobilized for support (e.g., family involvement), as well as those areas that could be targeted for clinical improvement (e.g., self-esteem, stress management, occupational problems). Treatment planning for John therefore flowed directly from the SSF. (2007, p. 15) 
Initial treatment priorities are also informed by clear criteria. The primary criterion for suicidal clients is safety. Thus, in addition to the crisis plan, Bryan focused on reducing the frequency and intensity of John's suicidal ideation. A second criterion is to start with something that can reinforce confidence and motivation in the treatment. This is usually something that is more amenable to change, which will provide some immediate relief. Often this involves work by the client rather than changing others' behavior or characteristics of the client's context, which would take more time and not necessarily increase client involvement and sense of agency. Thus, after safety considerations, Bryan started by addressing John's behavioral skills deficits that contributed to and maintained his affective distress. The resulting relief provided the hope and motivation necessary for addressing more complex issues. As one therapist tells his suicidal clients, "Hope means work and vice versa" (Catenaccio, 1995, pg. 85).

Another critical and, at times, underemphasized intervention with suicidal clients is to expand the therapist's interventions into the client's environment. Effective suicide intervention must move beyond the office. This consists of assessment and mobilization of a client's supports as well as the initiation or reintroduction of benign cycles. In this regard, Bryan involved John's spouse in his treatment, recommended his participation in a group with other veterans of the Iraq war, facilitated his redeployment to a less stressful job, and encouraged his resumption of physical activities.

\section{Other Major Features}

\section{Staying Connected to Current Research}

In addition to the above initial considerations, there are three major features of Bryan's treatment that should be noted, and several specific features of the treatment that bear comment. First, the case highlights the importance of keeping abreast of current clinical research. I tell my students that they are embarking on an endless learning process; and if they stop keeping up with current developments in the field, they should stop seeing clients.

\section{Laying Out a Coherent Theory}

Second, without a clear and evolving conceptual framework for one's interventions, clinical work will be characterized by stasis and lack of intentionality. Bryan clearly communicates the utility of Rudd's fluid vulnerability theory for his conceptualization of this case. However, with all due respect to the contributions of my colleague, David Rudd, I found fluid vulnerability theory to require a substantial effort to translate and apply this complex set of constructs. I find this to be true of many psychological theories in which rather esoteric constructs obscure more than a grain of truth and even elegance. If I want a pragmatic way to inform my own and my clients' understanding of what is going on in suicidal states, I will pass on "reciprocal and synchronous interaction of structural schema units."

On the other hand, Jobes' (2006) CAMS framework meets the criteria of empirical and conceptual grounding through an ongoing process of field-testing, research, and application. This 
collaborative approach that both affirms and requires the clients' contribution to understanding and addressing their suicidal crisis seems particularly applicable to John's injured self-esteem and need to regain agency in the face of his upsetting suicidal feelings.

\section{Applying a Range of Treatment Methods}

The third major feature of this treatment is the flexible application of a wide variety of treatment methods that are tailored to the exigencies of John's case, yet remain within the general cognitive framework. This is a clear example of how effective intentional clinicians draw on a substantial repertoire of interventions, and why the application of any specific, manualized treatment approach with strict fidelity frequently fails to address the realities of clinical contexts. An examination of the breadth of that repertoire reveals critical mediators or active ingredients of all treatments, as well as specific techniques that are employed in response to identified client needs and suicidal crises. Many of these were identified by Bryan and his client as contributing to the successful outcome of this treatment.

One of these active ingredients is the importance of the relationship, which has the most empirical support as a mediator of positive treatment outcome (Norcross, 2002). Several things appeared to enhance Bryan's relationship with John. For example, after the initial assessment, Bryan described "moving towards" his client so that he can see his suicidal experience through the client's eyes. This involves letting the client tell his story for the first time to someone who is not afraid or judgmental of his suicidal feelings. It is clear how this can begin to reduce the client's sense of isolation and fear of his suicidal thoughts. Among the most common feedback from clients as to what was helpful about their contact with a crisis center was that the counselor "listened and let me talk" (Kalafat, Gould, Munfakh, \& Kleinman, 2007). Another contribution to the relationship was Bryan's unwavering confidence in the treatment's capacity to address his client's concerns. For an individual overcome by unremitting stressful circumstances and demoralized by his inability to cope, this confidence must provide a critical response to the client's hopelessness. Bryan's credibility was also based on his familiarity with the military context; his access to resources, such as support groups and alternate deployment options; and, the aforementioned repertoire of strategies to address his client's concerns, including working with couples, group approaches, bibliotherapy, mindfulness, behavioral activation, and relaxation techniques.

These strategies were not simply presented as a clinician's skills, but as techniques to be taught to the client and applied to a variety of problems that he may encounter. This transfer of training for John's problem solving repertoire was facilitated by the innovative "what if" exercise. Skills acquisition and practice in their application to problems is a pragmatic approach to ensuring that the client emerges from his or her crisis with an enhanced sense of self efficacy as well as concrete skills that may prevent future crises.

Moreover, imbedded in the effort to develop John's coping skills for dealing with stress is a stance that I feel must be a part of any effective treatment of suicide. While Bryan did not label it as such, this is an existential stance that emphasizes the inescapable reality of pain, 
setbacks, and stress as part of life. No therapy promises a life without pain or stress. Rather, we must address clients' unwillingness to suffer (Chiles \& Strosahl, 1995). Thus, Bryan emphasized "The ability to accept negative life experiences -- and more importantly the capability to tolerate them no matter how undesirable"; and, that "it was important for John to understand and accept that there were many things in life that were beyond his control, but his reactions to these events were completely within his control" (pg. 32). To paraphrase two existential therapists, Kopp (1972) stated that we must accept full responsibility for a life over which we have little control; and Perls (1970) noted that responsibility = "response ability." Bryan did not simply present this as a philosophical position. Rather, in line with his pragmatic approach, Bryan taught stress tolerance skills, and he reframed John's negative feelings such as guilt and horror as normal reactions to his combat experience that are shared by others.

Relatedly, one of the lessons learned about the treatment of combat stress during the Second World War was to avoid pathologizing these reactions. Recent evidence from the National Comorbidity Survey indicates that acute reactions to a variety of losses have symptom profiles similar to clinical depression. The study's authors called for extending the present DSM exclusion of the diagnosis of clinical depression from grief to other losses (Wakefield, Schmitz, First, \& Horwitz, 2007). Thus, Bryan's initial diagnostic impressions included a provisional diagnosis of Adjustment Disorder With Mixed Anxiety and Depressed Mood, with "rule outs" for Posttraumatic Stress Disorder and Major Depressive Disorder. Later, a diagnosis of Post Traumatic Stress Disorder and an exposure-based treatment were considered. The diagnosis of PTSD and exposure-based treatment seemed questionable to me as John was currently exposed to continued traumatic stress on his job. Redeployment to a less stressful setting, rather than exposure treatment, provided relief.

The only other "would have" reaction I had to the case study is that in regard to the therapeutic relationship, I would like to know more about the quality of the relationship. That is, while I imagine Bryan coming across to John as a competent, confident, caring, responsive, and organized caregiver, I wondered what Bryan's own reactions to his client were. On what basis did he connect to this client, and what about John initially inspired confidence and positive regard within Bryan? I am convinced that clients sense our feelings about and reactions to them, as well as our attitudes toward their suicidal feelings and initial presentation of "incompetence." This, as well as our clinical helping skills and strategies, plays an important role in the course of treatment.

Case studies provide important insight into the actual work within clinical settings. Bryan's detailed and thoughtful description of his work with John is an invaluable resource that I will definitely incorporate into my suicide intervention training programs. 


\section{REFERENCES}

American Foundation for Suicide Prevention (AFSP) (2007). Suicide prevention project. http://www.afsp.org/index.cfm?page_id=058F81BC-D8FD-26AFA93A24B70AC0368C. Accessed 4-18-07.

Brent, D. A., \& Bridge, J. (2003). Firearms availability and suicide: Evidence, interventions, and future directions. American Behavioral Scientist, 46, 1192-1210.

Bryan, C. J. (2007). Empirically-based outpatient treatment for a patient at risk for suicide: The case of "John." Pragmatic Case Studies in Psychotherapy [Online], Vol. 3(2), Article 3, pp. 1-40. Available: http://hdl.rutgers.edu/1782.1/pcsp_journal.

Catenaccio, R. (1995). Crisis intervention with suicidal adolescents: A view from the emergency room. In J. K. Zimmerman, \& G. M. Asnis, (Eds.). Treatment approaches with suicidal adolescents. (pp. 71-90). NY: Wiley.

Chiles, J. A., \& Strosahl, K. D. (1995). The suicidal patient: Principles of assessment, treatment, and case management. Washington, DC: American Psychiatric Press.

Echterling, L. G., \& Hartsough, D. M. (1989). Phases of helping in successful crisis telephone calls. Journal of Community Psychology, 17, 249-257.

Ellis, T. E. (2004). Collaboration and a self-help orientation in therapy with suicidal clients. Journal of Contemporary Psychotherapy, 34, 41-57.

Geertz, C. (1973). Thick description: Toward an interpretive theory of culture. In C. Geertz (Ed.), The interpretation of cultures (pp. 3-30). New York: Basic Books.

Gould, M. S., Kalafat, J., Harris-Munfakh, J. L., \& Kleinman, M. (in press). An evaluation of crisis hotline outcomes. Part II: Suicidal callers. Suicide and Life-Threatening Behavior.

Hendin, H., Haas, A. P., Maltsberger, J. T., Koestner, B., \& Szanto, K. (2006). Problems in psychotherapy with suicidal patients. American Journal of Psychiatry; 16,:67-72.

Hendin, H., Haas, A. P., Maltsberger, J. T., Koestner, B., Szanto, K., \& Rabinowicz, H. (2004). Desperation and other affective states in suicidal patients. (2004). Suicide and LifeThreatening Behavior, 34, 386-394.

Jobes, D. A. (2006). Managing Suicidal Risk: A Collaborative Approach. New York: The Guilford Press.

Kalafat, J., Gould, M. S., Harris-Munfukh, J. L., \& Kleinman, M. (in press). An evaluation of crisis hotline outcomes. Part I: Non-suicidal crisis callers. Suicide and Life-Threatening Behavior.

Knox, K. L., Litts, D. A., Talcott, G. W., Feig, J. C., Eric, D., Caine, E. D. (2003). Risk of suicide and related adverse outcomes after exposure to a suicide prevention programme in the US Air Force: cohort study. British Medical Journal, 32, 1-5.

Kopp, S.B. (1972). If you meet the Buddha on the road, kill him. NY: Bantam Books.

Lee, K. H. (1999). Experiences of suicidal callers utilizing the crisis and information center: A qualitative and quantitative program evaluation. (Doctoral dissertation, Spalding University, 1999). Dissertation Abstracts International, 60, 0834.

Lester, D. (1997). The role of shame in suicide. Suicide and Life-Threatening Behavior, 27, 352361.

Norcross, J. C. (2002). Psychotherapy relationships that work. NY: Oxford.

Perls, F. S. (1970). Gestalt therapy verbatim. NY: Bantam Books. 
Pragmatic Case Studies in Psychotherapy, http://pcsp.libraries.rutgers.edu

Volume 3, Module 2, Article 2, pp. 41-49, 05-02-07 [copyright by authors]

Ramsay, R., Tanny, B., Lang, W., \& Kinzel, T. (2004). Suicide Intervention handbook. Calgary, AB: LivingWorks, Inc.

Rogers, C. R. (1957). The necessary and sufficient conditions of therapeutic personality change. Journal of Consulting Psychology, 21, 95-103.

Rudd, M. D., Joiner, T., Rajab, M. H. (2001). Treating suicidal behavior: An effective, timelimited approach. NY: Guilford.

Sullivan, H. S. (1970). The psychiatric interview. NY: W. W. Norton. 